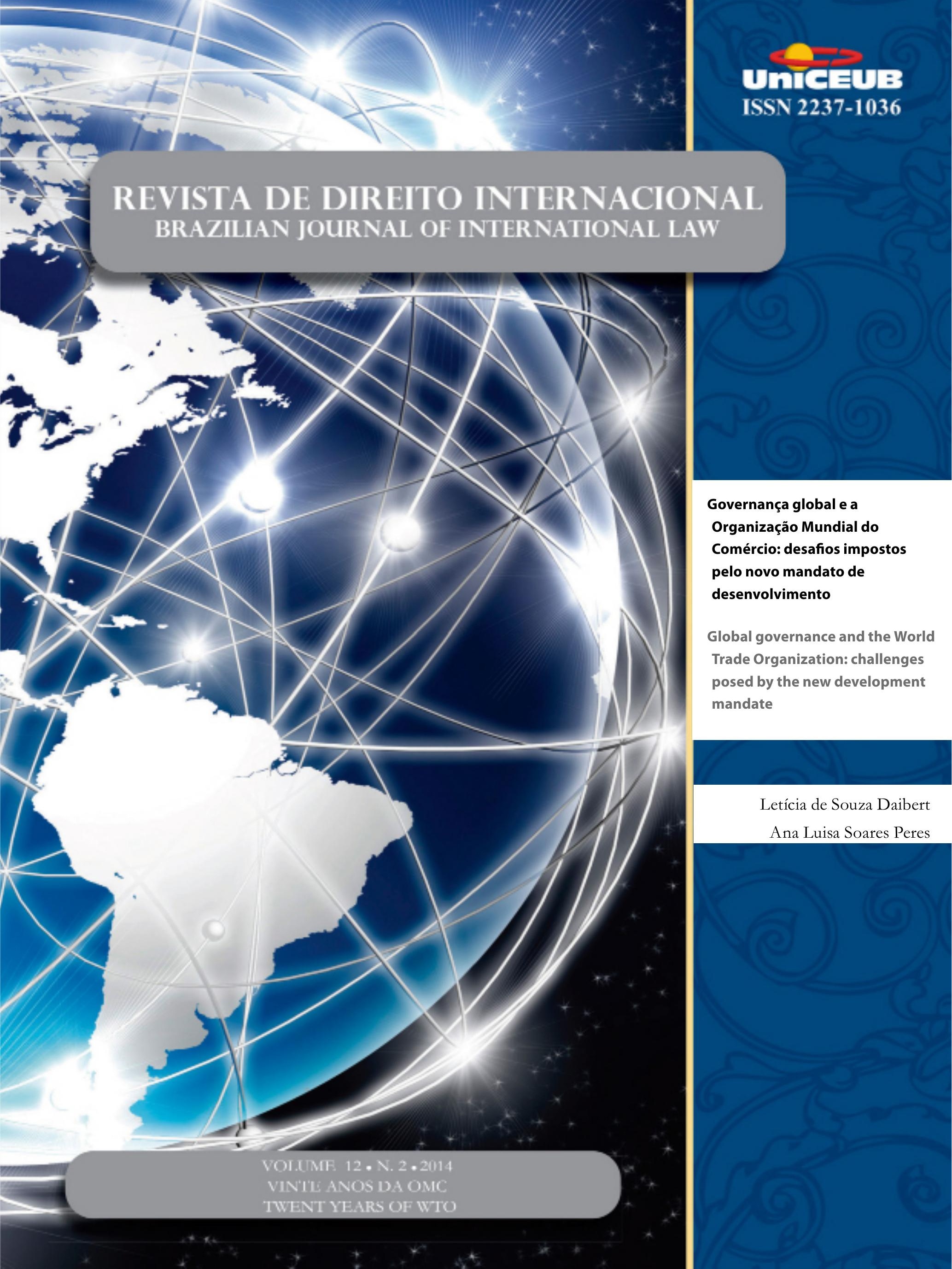


I. Crônicas

1. Crônicas da atualidade do Direito Internacional ......................................................16

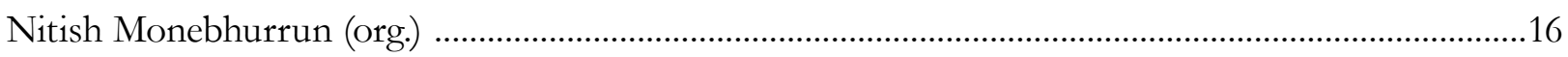

2.Decisões da Corte Internacional de Justiça e do Tribunal Internacional Sobre o Direito do Mar

Nitish Monebhurrun

José Eduardo Siqueira

3. Crônicas do direito internacional dos inVestimentos

Nitish Monebhurrun

\section{Os Vinte Anos dA OMC}

EXPORT CONTROLS AS INDUSTRIAL POLICY ON NATURAL RESOURCES: REGULATORY LIMITATIONS ON CHINA - RAW MATERIALS AND CHINA - RARE EARTHS CASES.

Gustavo Ferreira Ribeiro

O problema da espionagem econômica internacional: Seria a Organização Mundial do CoMÉRCIO O FORO ADEQUADO PARA SUA APRECIAÇÃO?

Humberto A.Vasconcelos Lima

Naiana Magrini Rodrigues Cunha

International Standards for Intellectual Property Rights Protection: a reflection on CLIMATE-FRIENDLY TECHNOLOGY TRANSFER.

Guihong Zhang

Jiani Jiang

Can Wang

Os vinte anos da OMC, suas conquistas e desafios: uma análise do Brasil e o Sistema de SoLUÇõES DE CONTROvÉRsias

Etiene M. Bosco Breviglieri

Luciano Meneguetti Pereira

A relação entre os tratados multilaterais ambientais e os acordos da OMC: é possível CONCILIAR O CONFLITO?

Fabio Costa Morosini,

Luisa Zuardi Niencheski 
Um desafio na Organização Mundial do Comércio: Viabilidade de um acordo plurilateral

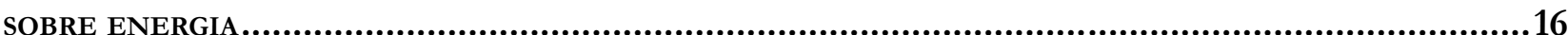

Matheus Linck Bassani

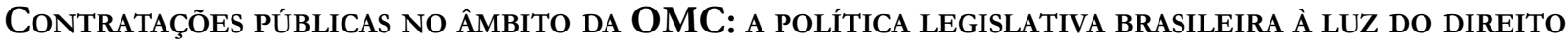
AO DESENVOLVIMENTO

André Jansen do Nascimento

Governança global e a Organização Mundial do Comércio: desafios impostos pelo novo MANDATO DE DESENVOLVIMENTO

Letícia de Souza Daibert

Ana Luísa Soares Peres

Vinte Anos de Crise para a África? Poder, Assimetrias e a Abordagem Liberal da OMC.....239 Igor Abdalla Medina de Souza

OS MECANISMOS DE INDUÇÃo AO CUMPRIMENTO NO ÂMBITO DA OMC 258

Fernando Lopes Ferraz Elias

A promoção de accountability na Organização Mundial do Comércio: uma análise horiZONTAL E VERTICAL

Celso Henrique Cadete de Figueiredo

LA OMC Y EL PROCESO DE GLOBALIZACION DE LA REGULACIÓN ALIMENTARIA

Maria Eugenia Marichal

O ACORDO GATS E SUA APLICAÇÃo AOS SERVIÇOS DO COMÉRCIO ELETRÔNICO

Gleisse Ribeiro Alves

A OMC e o REgionalismo do SÉCulo XXI: estratégIA DE imposição de MOdelos normativos? .. 337 Camilla Capucio

A ORGANIZAÇÃo MUNDIAL DO COMÉRCIO E A CHINA: DIREITO DE PROPRIEDADE E PROPRIEDADE INTELECTUAL NO PAÍS

Dos contenciosos Na OMC cOM ENFOQUe EM RESTRições Às EXPORTAÇÕES DA CHINA .363 Marco Antônio Alcântara Nascimento 
Alice Rocha da Silva

\section{Outros Temas}

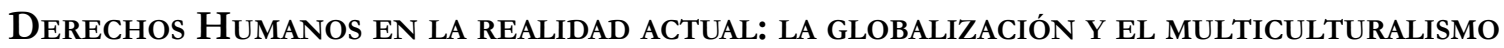

David Falcão

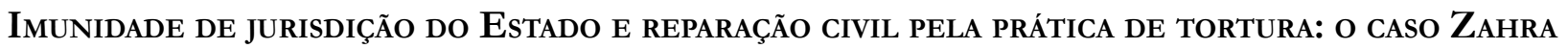

KAZEMI v. REPÚblica IslâMiCA do Irã

Patrícia Maria Lara Abreu

Rodrigo Otávio Bastos Silva Raposo

INTERREgIONAL Organizations (IROS) IN EUROPE: NEW SUBJECTS OF CONTEMPORARY INTERNATIONAL LAW?

Davorin Lapas

A CONEXÃo ENTRE os Direitos humanos E A CORRUPÇÃo.

Gabriela Alves Mendes Vieira

Marcelo Dias Varella

GRUPO DE SOCIEDADES: INSTRUMENTO JURÍDICO DE ORGANIZAÇÃO DA EMPRESA PLURISSOCIETÁRIA.....495

Daniel Amin Ferraz 


\title{
Governança global e a Organização Mundial do Comércio: desafios impostos pelo novo mandato de desenvolvimento*
}

\author{
Global governance and the World Trade \\ Organization: challenges posed by the new \\ development mandate
}

\footnotetext{
* Recebido em 30.10.2014

Aceito em 02.12.2014
}

** Professora voluntária de Direito Internacional Público na UFMG. Mestranda em Direito Internacional pela Universidade Federal de Minas Gerais e Graduada em Direito pela mesma instituição. Especialista em Estudos Diplomáticos pela Faculdade de Direito Milton Campos. Bolsista da FAPEMIG, leticiadaibert@gmail.com.

*** Mestranda em Direito Internacional pela Universidade Federal de Minas Gerais e Graduada em Direito pela mesma instituição. Bolsista da CAPES, nabrescia87@gmail.com.

\author{
Letícia de Souza Daibert** \\ Ana Luísa Soares Peres*** \\ "As pessoas estão a unir-se, em todo o mundo, numa luta comum: \\ participar livremente nos acontecimentos e processos que condicionam \\ as suas vidas". Mahbub ul Haq
}

\section{Resumo}

O presente trabalho propõe uma abordagem das normas da Organização Mundial do Comércio (OMC), especialmente de seus princípios e objetivos, baseada no conceito de governança global. Apresentam-se, de forma sucinta, algumas características fundamentais da governança global contemporânea para, em seguida, analisarem-se aspectos pontuais relacionados com a atuação da $\mathrm{OMC}$ como fórum de promoção de práticas de boa governança. Reconhece-se que a intensificação do processo de integração econômica reafirmou a interdependência entre os atores da sociedade internacional, e levou ao surgimento de desafios cuja solução ultrapassa a capacidade dos Estados individualmente considerados. A necessidade de se conferir legitimidade a essas soluções gera a demanda pelo estabelecimento de boa governança. Analisa-se, posteriormente, a importância de uma interpretação extensiva das normas da OMC, que inclua os preâmbulos de seus acordos, de modo a identificar valores e propósitos comuns a todos os Membros. Por meio desses interesses compartilhados, ressaltam-se os benefícios da participação dos Estados em desenvolvimento e de menor desenvolvimento relativo nas atividades da OMC, em um contexto de governança global, que enfatiza a coordenação e o diálogo entre os diversos atores. Por fim, considera-se a reforma do sistema de tomada de decisão da OMC, com o intuito de garantir a participação efetiva dos Membros em desenvolvimento e de menor desenvolvimento relativo. Para tanto, sugere-se a adoção de um modelo de democracia discursiva, segundo o qual se deve considerar todos os argumentos levantados pelas partes, a fim de alcançar uma decisão adequada que seja fruto de um consenso fundamentado.

Palavras-chave: OMC. Desenvolvimento. Governança Global. Participação deliberativa. Democracia.

\section{Abstract}

This paper suggests an approach to rules of the World Trade Organization (WTO), especially its principles and objectives, based on the concept of global governance. Some key features of contemporary global governance are briefly 
presented, and then specific aspects related to the performance of the WTO as a forum for promoting good governance practices are analyzed. It recognizes that the intensification of the economic integration reaffirmed the interdependence among actors in international society and led to the emergence of challenges that exceed the capacity of solution of problems by States individually considered. The need to confer legitimacy to such solutions generates a demand for the establishment of good governance. Subsequently, the importance of an extensive interpretation concerning the WTO's rules is analyzed, including its agreements preambles, in order to identify values and purposes common to all Members. Through these shared interests, the benefits of developing and least developed States participation in WTO activities are highlighted in a context of global governance, which emphasizes the coordination and the dialogue among the different actors. Finally, the reform of the WTO decision-making process is considered, aimed at ensuring the effective participation of developing and least developed Members. To this end, the adoption of a discursive democracy model is suggested, according to which all the arguments raised by the parties should be taken into account, to achieve a proper decision that is the result of a reasonable consensus.

Keywords: WTO. Development. Global governance. Deliberative participation. Democracy.

\section{Introdução}

O comércio não é um fim em si mesmo, mas um mecanismo de promoção do crescimento e do desenvolvimento. Esse é o princípio subjacente ao papel desempenhado pela Organização Mundial do Comércio (OMC) e pelo arcabouço normativo regulando o sistema multilateral de liberalização do comércio e cooperação econômica internacional ${ }^{1}$.

A existência de um regime multilateral de comércio crível e legítimo, apto a promover a governança econômica e o desenvolvimento, deve necessariamente passar pelo reconhecimento dos interesses comerciais, financeiros e sociais de todos os atores envolvidos, especialmente os países em desenvolvimento e de menor desenvolvimento relativo, de forma a permitir

1 PANITCHPAKDI, Supachai. The WTO, global governance and development. In: SAMPSON, Gary P. (Ed.). The WTO and global governance: future directions. Tóquio: United Nations University Press, 2008. p. 187. que eles maximizem os seus ganhos e minimizem as suas perdas na participação no comércio internacional.

O presente artigo conta com cinco seções, além deste primeiro item introdutório. No segundo item, a governança global será analisada como mecanismo facilitador da cooperação entre atores internacionais. $\mathrm{O}$ terceiro item explora o contexto histórico de surgimento das organizações internacionais de propósito específico no século XX e a relação deste fenômeno com a consolidação de práticas de boa governança na arena global. No item quatro, analisa-se a forma de atuação da OMC como agente ativo da promoção de práticas de boa governança global. O quinto item demonstra a existência de uma agenda comum relacionada com o desenvolvimento econômico em diferentes fóruns de debate internacional e apresenta indícios da demanda dos Estados pela consolidação de práticas de boa governança sobre comércio internacional. O sexto item versa sobre a necessidade de reforma do processo de tomada de decisão da OMC, de modo a garantir uma participação efetiva dos Membros em desenvolvimento e de menor desenvolvimento relativo, em consonância com os princípios de boa governança. Nas considerações finais, reforçam-se as impressões derivadas das análises das transformações do sistema multilateral de comércio e das tendências para a consolidação de um ambiente mais equilibrado de negociações.

O estudo desenvolvido fundamenta-se na revisão de extensa bibliografia específica sobre o tema, bem como na interpretação teleológica dos acordos que integram o âmbito normativo da OMC e na análise de casos levados ao Órgão de Solução de Controvérsias (OSC). A partir dessa pesquisa inicial, elaboram-se propostas que favoreçam o fortalecimento da estrutura de governança global dentro da Organização, de modo a promover os interesses e as necessidades relacionados ao desenvolvimento.

\section{Relevância da governança global para o funcionamento das organizações internacionais}

O aumento da interdependência global é um dos principais desafios contemporâneos. O processo de tomada de decisões é atualmente conduzido com ampla participação de vários atores internacionais e frequentemente transcende as fronteiras nacionais. Esse fenômeno requer o estabelecimento de uma estrutura de governança global que facilite a cooperação, mas que também reconheça os limites desta mesma governança no nível supranacional. 
Uma governança global eficaz pressupõe a habilidade de se administrar a interdependência de maneira a fomentar a cooperação em dada arena política, levando em consideração as diferenças em competitividade, os valores e as expectativas daqueles envolvidos nas negociações ${ }^{2}$.

Para que as organizações internacionais possam ser vistas como verdadeiros fóruns de governança global, investidos de mecanismos legítimos e de autoridade para conduzir negociações, elas devem demonstrar a sua capacidade de reconhecimento e de gerenciamento das diferenças, especialmente entre interesses nacionais e internacionais.

Nesse contexto, as organizações internacionais criam estruturas institucionais equivalentes ao aparato estatal de seus membros, tanto em forma quanto na função ${ }^{3}$, que terminam por facilitar o surgimento de redes governamentais de coleta e disseminação de informações dentro das próprias organizações ${ }^{4}$.

Anne-Marie Slaughter, em sua obra $A$ New World Order, identifica que

[o] desafio para os arquitetos destas redes (que poderiam ser os próprios membros das instituições nacionais e supranacionais participantes) será o de promover o equilíbrio adequado entre funções e responsabilidades nacionais e supranacionais. (Tradução nossa). ${ }^{5}$

As redes governamentais existem dentro e paralelamente às organizações formalmente constituídas como sujeitos de direito internacional. Elas são formadas por representantes dos governos nacionais e muitas vezes facilitam que as várias demandas da sociedade internacional sejam consideradas nas negociações ${ }^{6}$.

2 ESTY, Daniel C. Governing at the trade-environment interface. In: SAMPSON, Gary P. (Ed.).The WTO and global governance: future directions. Tóquio: United Nations University Press, 2008. p. 118.

3 SLAUghter, Anne-Marie. A New World Order. Princeton: Princeton University Press, 2004. p. 16.

4 Slaughter, Anne-Marie. A New World Order. Princeton: Princeton University Press, 2004. p. 153.

5 The trick for the architects of these networks (which could be the participating national and supranational government institutions themselves) will be to strike the right balance between national and supranational functions and responsibilities. SLAUGHTER, Anne-Marie. A New World Order. Princeton: Princeton University Press, 2004. p. 133.

6 SLAughter, Anne-Marie. A New World Order. Princeton: Princeton University Press, 2004. p. 58.
Essas redes são parte de um sistema de governança global que busca institucionalizar a cooperação e conter a escalada de conflitos, de maneira a permitir que haja um aumento mundial da paz e da prosperidade, com a melhoria dos níveis de vida de todos. Desse modo, uma vez que a sociedade internacional é caracterizada pela inexistência de hierarquia, de um governo central absoluto, as relações desenvolvidas em seu meio devem ser fundamentadas em um processo de diálogo e em vínculos de coordenação.

A OMCéa entidade cujo mandato cobre o mais amplo espectro de temas relacionados com a globalização e também a que congrega os mais diferentes pontos de vista sobre o fenômeno. A crescente integração de mercados e interdependência econômica entre os países fizeram com que temas relativos ao comércio internacional passassem a ser centrais nos processos de elaboração de políticas públicas ${ }^{7}$. Nesse cenário, a OMC emergiu como o principal fórum de articulação dos interesses envolvidos com o comércio. As redes formadas dentro da Organização desempenham um papel facilitador desta articulação de interesses.

Para que a OMC possa desempenhar adequadamente as suas funções e se fortalecer como ambiente preponderante de construção de um regime global de interdependência econômica, ela deve ser capaz de reconhecer e de reforçar os princípios e objetivos sobre os quais a Organização foi constituída, enquanto promove a liberalização do comércio. São exatamente esses princípios e objetivos que possibilitam a acomodação das diferenças entre seus Membros dentro do arcabouço normativo da entidade e fomentam as práticas de boa governança. Nesse sentido, a boa governança pode ser definida com base em cinco conjuntos de princípios: i) legitimidade, que envolve a participação e o consenso; ii) direção, de modo a se construir uma visão estratégica ampla e que considere o todo; iii) performance, que implica as ideias de eficiência e efetividade; iv) responsabilidade, na medida em que os tomadores de decisão devem ser responsáveis perante aqueles que representam, os quais, por sua vez, devem ter acesso às informações necessárias, o que ressalta a importância da transparência; e v) justiça, relacionada à equidade e ao estado de direito ${ }^{8}$.

7 LAMY, Pascal. The WTO's contribution to global governance. In: SAMPSON, Gary P. (Ed.). The WTO and global governance: future directions. Tóquio: United Nations University Press, 2008. p. 39.

8 GRAHAM, John; AMOS, Bruce; PLUMPTRE, Tim. Principles for Good Governance in the 21st Century. August 2003. Ottaw: Institute 
3 Desenvolvimento das organizações internacionais de finalidade específica no século xx: governança e mudanças paradigmáticas motivadas pelo adensamento das relações internacionais

A Grande Depressão (1929) ${ }^{9}$ transformou as relações comerciais internacionais no período entre guerras, alterando o paradigma da antiga economia liberal. Os Estados iniciaram um processo de isolamento, com o soerguimento de barreiras comerciais cada vez maiores para proteger seus mercados internos e as suas respectivas moedas contra os efeitos das crises mundiais.

O tratamento não discriminatório entre produtos, serviços e parceiros comerciais nacionais e estrangeiros, conhecido como princípio da nação mais favorecida, foi eliminado em $60 \%$ dos 510 acordos comerciais celebrados entre 1931 e 1939, permanecendo nos demais com limitação de escopo. Este fato é exemplificativo do processo de progressivo isolamento dos Estados, que enfraquecia as bases de florescimento de um sistema multilateral de comércio de longo prazo. Em decorrência disto, o comércio mundial caiu $60 \%$ em quatro anos $(1929-32)^{10}$.

Após a Segunda Guerra Mundial, as potências aliadas concluíram que o isolacionismo econômico dos

of Governance, 2003. (Policy Brief, n. 15). Disponível em: < http:// unpan1.un.org/intradoc/groups/public/documents/UNPAN/ UNPAN011842.pdf>. Acesso em: 12 out. 2014.

9 Em primeiro lugar, a extrema violência da depressão deve ser percebida. Nas três potências industriais líderes do mundo - Estados Unidos, Grã-Bretanha e Alemanha - 10.000.000 de trabalhadores ficaram ociosos. Há poucas indústrias em qualquer parte gerando lucro suficiente para a sua expansão - o que é um teste para a verificação do progresso. Ao mesmo tempo, nos países de produção primária, a renda obtida com a mineração e a agricultura é auferida com a venda, no caso de quase todas as commodities importantes, a um preço que, para muitos ou para a maioria dos produtores, não cobre os seus custos. [...] não há exemplo na história moderna de uma queda de preços tão grande e tão rápida [...]. Eis a magnitude da catástrofe. (Tradução nossa). First of all, the extreme violence of the slump is to be noticed. In the three leading industrial countries of the world - the United States, Great Britain, and Germany-10,000,000 workers stand idle. There is scarcely an important industry anywhere earning enough profit to make it expand - which is the test of progress. At the same time, in the countries of primary production the output of mining and of agriculture is selling, in the case of almost every important commodity, at a price which, for many or for the majority of producers, does not cover its cost. [...] there is no example in modern bistory of so great and rapid a fall of prices [...]. Hence the magnitude of the catastrophe. KEYNES, John Maynard. The Great Slump of 1930. Londres: The Nation \& Athenæum, 1930. Part 1. Disponível em: $<$ http://www.gutenberg.ca/ebooks/keynes-slump/keynes-slump00-h.html>. Acesso em: 29 out. 2014.

10 HOBSBAWN, Eric. The age of extremes: the short twentieth century (1914-1991). Londres: Abacus, 1994. p. 94.
Estados teria sido uma das mais proeminentes causas para o aprofundamento da Grande Depressão e para a eclosão do conflito.

De fato, a coerência entre políticas trabalhistas, financeiras e comerciais era um ponto central do sistema multilateral de nações que se constituía após o arrefecimento da guerra. A Organização Internacional do Trabalho (OIT), o Fundo Monetário Internacional (FMI), o Banco Internacional para Reconstrução e Desenvolvimento (BIRD) e a Organização Internacional do Comércio (OIC) seriam as entidades investidas do mandato para coordenar estas esferas da política internacional ${ }^{11}$.

A Conferência de Bretton Woods resultou na criação de duas organizações internacionais, a saber: o FMI, com atribuição de promover a estabilidade do sistema financeiro internacional; e o BIRD, cuja principal atribuição inicial foi a de financiar a reconstrução dos países europeus no pós-guerra ${ }^{12}$.

Os Estados Unidos da América (EUA) propuseram, em 1945, a instituição da OIC, cujo mandato estaria vinculado à regulamentação das relações comerciais internacionais, das relações de emprego e das práticas negociais. A organização, entretanto, não chegou a ser criada. A recusa do Congresso dos EUA em aprovar a carta instituidora da OIC, em dezembro de 1950, levou ao fim definitivo das negociações ${ }^{13}$.

Nesse contexto, entrou em vigor o Acordo Geral sobre Tarifas e Comércio(GATT/47), com o propósito de regular a progressiva redução de tarifas aduaneiras e de outras restrições comerciais. Como a Carta de Havana $^{14}$ nunca entrou em vigor, criou-se um vazio institucional relacionado com a normatização do comércio internacional. Para suprir esta lacuna, o GATT/47 foi aplicado de forma "provisória" por quarenta e sete anos.

11 SOMAVIA, Juan. Promoting policy coherence in the global governance of trade and employment. In: SAMPSON, Gary P. (Ed.). The WTO and global governance: future directions. Tóquio: United Nations University Press, 2008. p. 130.

12 PALMETER, David; MAVROIDS, Petros C. Dispute settlement in the World Trade Organization: practice and procedure. 2. ed. Cambridge: Cambridge University Press, 2004. p. 1.

13 PALMETER, David; MAVROIDS, Petros C. Dispute settlement in the World Trade Organization: practice and procedure. 2. ed. Cambridge: Cambridge University Press, 2004. p. 2.

14 Nome atribuído ao tratado que, se entrasse em vigor, viria a instituir a Organização Internacional do Comércio. 
O GATT/47 passou a desempenhar, então, as funções que seriam próprias da OIC. Para tanto, foram atribuídos ao acordo alguns aspectos institucionais. O que seria apenas um tratado internacional voltado para a liberalização do comércio se converteu em uma organização de fato. As estruturas institucionais foram sendo criadas e ajustadas conforme as necessidades dos seus Estados membros, identificadas no curso de suas relações comerciais ${ }^{15}$.

Merece destaque o fato de que os mandatos das organizações internacionais criadas no pós-guerra têm natureza complementar, e não exclusiva. Todas são responsáveis, em alguma medida, pela promoção da coesão das políticas internacionais sobre trabalho, finanças e comércio. Veja-se, a título exemplificativo, um dos objetivos da OIT, previsto no Anexo Declaração Referente aos Fins e Objetivos da Organização Internacional do Trabalho, da Constituição da Organização Internacional do Trabalho (1944): II $[\ldots]$

d) compete à Organização Internacional do Trabalho apreciar, no domínio internacional, tendo em vista tal objetivo, todos os programas de ação e medidas de caráter econômico e financeiro, ${ }^{16}$ (Grifo nosso).

O Convênio Constitutivo do Fundo Monetário Internacional apresenta outro exemplo da sobreposição de mandatos entre as organizações internacionais criadas no período:

Artigo I
Objetivos
Os objetivos do Fundo Monetário Internacional
são:[...]
(ii) Facilitar a expansão e o crescimento equilibrado
do comércio internacional e contribuir, assim,
para o estabelecimento e manutenção de níveis

15 HOEKMAN, Bernard M.; MAVROIDIS, Petros C. The World Trade Organization: law, economics and politics. Nova Iorque: Routledge, 2007. p. 7-8.

16 BRASIL. Decreto n. 25.696, de 20 de Outubro de 1948. Constituição da Organização Internacional do Trabalho (OIT) e seu Anexo (Declaração de Filadélfia), aprovada na $26^{a}$ reunião da Conferência (Filadélfia - 1944), conforme incorporado ao ordenamento jurídico brasileiro. elevados de emprego e de rendimento real e para o desenvolvimento dos recursos produtivos de todos os membros, como objetivos primordiais da política econômica ${ }^{17}$.

Os exemplos acima apresentados demonstram que a agenda internacional ampliou-se de forma considerável após a Segunda Guerra Mundial, abarcando inclusive temas antes restritos ao âmbito de competência interna dos Estados, como comércio e trabalho. O surgimento e fortalecimento de organizações internacionais, bem como o desenvolvimento de instrumentos normativos internacionais, contribuíram para a consolidação de uma complexa rede de interdependência pautada em arranjos regulatórios e de colaboração.

A criação das organizações no período pós-guerra é, certamente, uma das facetas do fenômeno da governança global. A preocupação em se construir um sistema multilateral de cooperação que perdurasse no longo prazo e fosse capaz de fomentar a manutenção da paz e da segurança mundial, ao mesmo tempo em que auxiliasse na manutenção da estabilidade econômica, renovaram a necessidade de se estabelecerem políticas globalmente coesas relacionadas com uma grande variedade de temas ${ }^{18}$, incentivando a participação de atores em vários níveis.

O adensamento do contexto de interdependência decorrente da globalização introduziu profundas modificações na forma de atuação e da formulação de políticas pelos Estados, ao pleitear tanto a criação de normas, como o exercício de governança para além das próprias fronteiras.

Ressalte-se que

$[\mathrm{g}]$ overnança global não é apenas um projeto
inspirado em princípios normativos. Ao contrário,
trata-se de uma realidade emergente. Admitir
a existência de uma governança no âmbito
internacional, ainda que incipiente, implica
reconhecer que os Estados soberanos
encontram-se atualmente imersos em uma
vasta teia de organizações, instituições

17 Convênio Constitutivo do Fundo Monetário Internacional FMI. BRASIL. Decreto n. 21.177, de 27 de maio de 1946. Convênio constitutivo do Fundo Monetário Internacional - FMI, de 22 de julho de 1944. Disponível em: <http://data.worldbank.org/ indicator/SP.URB.TOTL.IN.ZS> Acesso em: 12 maio 2014.

18 SOMAVIA, Juan. Promoting policy coherence in the global governance of trade and employment. In: SAMPSON, Gary P. (Ed.). The WTO and global governance: future directions, Tóquio: United Nations University Press, 2008. p. 131. 
e regimes internacionais que exercem autoridade e regulam uma série de atividades, envolvendo também diversos atores, dentre os quais se destacam, por sua relativa novidade, organizações não governamentais e as corporações multinacionais ${ }^{19}$.

Governança global, neste contexto de desenvolvimento das organizações internacionais, adquire o sentido de "[...] exercício de autoridade política na gestão de recursos para o desenvolvimento econômico e social." ${ }^{20}$. O fortalecimento da capacidade de os países formularem e executarem políticas públicas consistentes, e com vistas à promoção do crescimento e do desenvolvimento econômico também em âmbito internacional, passou a fazer parte da agenda global.

\section{A OMC como agente fomentador de uma governança global em matéria de comércio internacional e desenvolvimento econômico}

O Acordo de Marraqueche constituindo a OMC foi assinado em 12 de abril de 1994 e entrou em vigor em $1^{\circ}$ de janeiro de 1995 (BRASIL, Decreto no 1.355, de 30 de dezembro de 1994, 1994.) A estrutura da Organização foi planejada de acordo com as experiências acumuladas pelos Estados ao longo dos quarenta e sete anos de vigência do GATT/47.

Da mesma forma que o GATT/47, a OMC apresenta, entre seus objetivos, o fomento ao bem-estar de todas as nações, por meio da expansão da produção mundial e do intercâmbio comercial, a utilização plena dos recursos naturais e a expansão da produção e do comércio de bens. Ela funciona como um mecanismo para que os governos reduzam as suas barreiras comerciais e discutam políticas relacionadas com o comércio internacional ${ }^{21}$.

19 BENTO, Leonardo Valles. Governança global: uma abordagem conceitual e normativa das relações internacionais em um cenário de interdependência e globalização. 2007. Tese (Doutorado)-Curso de Pós-Graduação em Direito, Universidade Federal de Santa Catarina, Florianópolis, 2007. p. 192.

20 BENTO, Leonardo Valles. Governança global: uma abordagem conceitual e normativa das relações internacionais em um cenário de interdependência e globalização. 2007. Tese (Doutorado)-Curso de Pós-Graduação em Direito, Universidade Federal de Santa Catarina, Florianópolis, 2007. p. 135.

21 HOEKMAN, Bernard M.; MAVROIDIS, Petros C. The World Trade Organization: law, economics and politics. Nova Iorque: Routledge, 2007. p. 1.
A assinatura de tratados mutualmente benéficos, envolvendo a redução de tarifas e outras barreiras ao comércio, bem como a eliminação do tratamento discriminatório no comércio internacional, é apresentada como instrumento que contribuiria para a realização destes propósitos. A liberalização do comércio, portanto, não é um fim em si mesmo, mas um meio para a realização dos objetivos da Organização ${ }^{22}$.

Todos os acordos da OMC são aplicáveis a todos os seus $\mathrm{Membros}^{23}$. A instituição de um sistema de solução de controvérsias, dotado de meios para a execução de suas decisões, é uma de suas características mais relevantes. Sob a OMC, a formação de painéis, a adoção das decisões, bem como a autorização para retaliar, só são impedidas pelo consenso negativo, ou seja, caso todos os Membros da OMC votem negativamente à formação de painel, à adoção de decisão ou à retaliação de determinado Estado.

Cada um dos signatários dos acordos da OMC tem vOz e participa ativamente dos processos de tomada de decisões na Organização, sendo que a cada um é atribuído um voto de igual valor. Uma vez que a maior parte das deliberações é feita por consenso, até mesmo Estados menores têm a oportunidade de se fazerem ouvir no curso das negociações. Além disto, o fato de a Organização ser composta por um ordenamento jurídico cujas normas podem ser efetivadas por meio de um sistema de solução de controvérsias possibilita que o Membro menos expressivo demande as maiores potências mundiais.

Podem-se identificar exemplos do maior engajamento de países em desenvolvimento e de menor desenvolvimento relativo nas recentes reuniões ministeriais. As negociações de Seattle (1999) não progrediram, principalmente, pela recusa daqueles em aceitar a agenda imposta por alguns países desenvolvidos, relacionada com a inclusão de padrões mínimos de proteção de direitos trabalhistas nas normas da $\mathrm{OMC}^{24}$. Em Cancun (2003), as negociações foram interrompidas em razão da recusa dos países mais pobres em aceitar o lançamento de negociações sobre

22 HOEKMAN, Bernard M.; MAVROIDIS, Petros C. The World Trade Organization: law, economics and politics. Nova Iorque: Routledge, 2007. p. 14.

23 Princípio conhecido como single undertaking.

24 Os países em desenvolvimento e de menor desenvolvimento relativo entendem que a inclusão de padrões mínimos de proteção de direitos trabalhistas nas normas da OMC reduziria a competitividade da indústria intensiva em mão de obra desses mesmos países. 
as Questões de Singapura ${ }^{25}$ - concorrência, política de investimento e transparência em compras públicas ${ }^{26}$.

$\mathrm{Na}$ prática, a maior parte das negociações reflete as relações de poder existentes. Os países com maior poder econômico acabam exercendo maior influência no resultado das negociações. Não obstante, a característica que diferencia a $\mathrm{OMC}$ das experiências anteriores é a passagem de um sistema em que a implementação das esparsas normas existentes se dava de forma eminentemente voluntária e em que as disputas eram resolvidas por meios diplomáticos; para um sistema mais igualitário, em que as normas vigentes e as decisões exaradas pelo órgão de solução de controvérsias são juridicamente vinculantes. Isso permite um real engajamento dos países mais pobres nas negociações, ao promover a confiança - fator estruturante das relações internacionais - entre os membros.

Assim, as regras do sistema multilateral de comércio, em um contexto de governança global, são essenciais para assegurar a eficiência, previsibilidade e transparência das relações comerciais internacionais, de modo a manter e intensificar os fluxos de trocas entre os países. A existência de tal estabilidade favorece a integração dos membros em desenvolvimento na OMC, uma vez que fornece garantias de que a Organização não será um instrumento para a imposição dos interesses dos membros mais fortes. Constata-se, pois uma evolução do processo de tomada de decisão da OMC, que deixa de ser power oriented, para se transformar em rule oriented.

Fazer parte da Organização implica limitar a autonomia interna em quatro áreas principais: comércio de bens, comércio de serviços, proteção aos direitos de propriedade intelectual e solução de conflitos. Implica, ainda, submeter as políticas comerciais nacionais à avaliação periódica. Em contrapartida, os Membros recebem a segurança jurídica e um ambiente propício para a acomodação das demandas tanto dos países desenvolvidos, como dos países em desenvolvimento e de menor desenvolvimento relativo ${ }^{27}$.

25 Existe um temor por parte dos países em desenvolvimento e de menor desenvolvimento relativo de que a inclusão das Questões de Singapura levaria a uma grande redução da autonomia política dos Estados, ao aumento de custos das operações comerciais e à adoção de regras contrárias aos seus próprios interesses.

26 HOEKMAN, Bernard M.; MAVROIDIS, Petros C. The World Trade Organization: law, economics and politics. Nova Iorque: Routledge, 2007. p. 5.

27 HOEKMAN, Bernard M.; MAVROIDIS, Petros C. The World Trade Organization: law, economics and politics. Nova Iorque:
A OMC, nesse cenário, é um ator internacional que exerce governança global com relação a um amplo espectro de temas. Ela não só possibilita a cooperação, ao proporcionar um ambiente horizontal de troca de compromissos políticos comerciais e de debates para o estabelecimento de normas de conduta comuns, como também exerce efetiva autoridade sobre as normas jurídicas e sobre a política interna de seus membros. A conformação de um sistema eficiente de governança global relacionada com comércio é essencial para a consecução dos objetivos internacionais de desenvolvimento.

Com razão, nos ensinamentos de Lawrence $\mathrm{S}$. Finkelstein:

Governança Global é governar, sem autoridade soberana, relações que transcendem fronteiras nacionais. Governança Global é fazer internacionalmente o que governos fazem em casa. (Tradução nossa) ${ }^{28}$

$\mathrm{Na}$ OMC, ao longo de sua história, houve a progressiva solidificação de um sistema de normas e regulamentos que demandam efetiva ação governamental. O seu papel não é o de uma autoridade soberana e superior aos seus membros, mas o de conformação de um ambiente que favorece debates democráticos, entre Estados com igual poder de voto e de representação.

\subsection{Interpretação dos acordos da OMC: reconhecimento da existência de valores compartilhados pelos membros da organização}

A interpretação de toda norma jurídica tem início na análise do seu texto, sendo este apenas o primeiro método ao qual deve recorrer o operador do direito para esclarecer o seu sentido. A compreensão das normas jurídicas, todavia, não se esgota na interpretação textual ou literal de seu texto. O texto, o contexto histórico, os objetivos e propósitos para os quais a norma foi instituída devem ser entendidos como uma única regra de interpretação.

Os dispositivos de um tratado devem receber interpretação conforme seu sentido original. O objeto

Routledge, 2007. p. 15.

28 Global Governance is governing, without sovereign authority, relationships that transcend national frontiers. Global governance is doing internationally what governments do at home. FINKELSTEIN, Lawrence S. What is global governance? Global Governance, v. 1, n. 3, p. 367-373, sept./dec. 1995. p. 369. 
e os propósitos do dispositivo legal também devem ser levados em consideração ao se estabelecer o sentido de uma norma.

É exatamente esta interpretação sistemática das normas contidas nos acordos que formam o conjunto normativo da OMC que cria a possibilidade de se acomodarem os interesses de países em desenvolvimento e de menor desenvolvimento relativo e possibilita o efetivo exercício de governança global em matéria comercial. A análise das normas em conjunto permite ao aplicador do direito identificar quais os valores são compartilhados pelos Membros daquela Organização. Os valores compartilhados e objetivos comuns são o fundamento último da cooperação entre os Estados e, por isso, formam as bases para uma verdadeira governança global.

O Artigo 3.2 do Entendimento, relativo às Normas e Procedimentos sobre Solução de Controvérsias (ESC), determina que o Órgão de Apelação busque o real sentido das normas da OMC de acordo com o que determina as regras costumeiras sobre intepretação do Direito Internacional.

Artigo 3

Disposições Gerais [...]

2. O sistema de solução de controvérsias da OMC é elemento essencial para trazer segurança e previsibilidade ao sistema multilateral de comércio. Os Membros reconhecem que esse sistema é útil para preservar direitos e obrigações dos Membros dentro dos parâmetros dos acordos abrangidos e para esclarecer as disposições vigentes dos referidos acordos em conformidade com as normas correntes de interpretação do direito internacional público. As recomendações e decisões do OSC não poderão promover o aumento ou a diminuição dos direitos e obrigações definidos nos acordos abrangidos ${ }^{29}$.

O Órgão de Solução de Controvérsias da OMC (OSC) ratificou este entendimento, ao reconhecer os Artigos 31 e 32 da Convenção de Viena sobre o Direito

29 Anexo II ao Acordo Constitutivo da Organização Mundial Do Comércio - Entendimento relativo às Normas e Procedimentos sobre Solução de Controvérsias. Conforme incorporado ao ordenamento jurídico brasileiro. BRASIL. Decreto n. 1.355, de 30 de dezembro de 1994. dos Tratados de 1969 (Convenção de Viena) como normas gerais de interpretação. Referidas normas, conforme decisão do OSC no caso Japan - Alcoholic Beverages II, têm observância obrigatória, por terem adquirido status de costume internacional em matéria de direito dos tratados ${ }^{30}$ :

Artigo 31

Regra Geral de Interpretação

1. Um tratado deve ser interpretado de boafé segundo o sentido comum atribuível aos termos do tratado em seu contexto e à luz de seu objetivo e finalidade.

Artigo 32

Meios Suplementares de Interpretação

Pode-se recorrer a meios suplementares de interpretação, inclusive aos trabalhos preparatórios do tratado eàs circunstâncias de sua conclusão, a fim de confirmar o sentido resultante da aplicação do artigo 31 ou de determinar o sentido quando a interpretação, de conformidade com o artigo 31:

a) deixa o sentido ambíguo ou obscuro; ou

b) conduz a um resultado que é manifestamente absurdo ou desarrazoado ${ }^{31}$.

O OSC confirmou, em várias oportunidades, a aplicação desse costume às disputas submetidas à sua apreciação. Na primeira lide decidida pelo Órgão de Apelação, em relação ao caso US-Gasoline, reconheceuse, expressamente, que o Artigo 31 da Convenção de Viena havia atingido o status de costume em Direito Internacional.

O painel, no caso Canada - Pharmaceutical Patents, referiu-se expressamente ao preâmbulo como contexto jurídico de interpretação das normas previstas no TRIPS:

30 WORLD TRADE ORGANIZATION. Japan: taxes on alcoholic beverages: report of the appellate body. (Japan Alcoholic Beverages II), WT/DS8/AB/R; WT/DS10/AB/R; WT/DS11/AB/R. 4 October 1996. Como adotado em 1 de novembro de 1996. p 12.

31 BRASIL. Decreto n. 7.030, de 14 de dezembro de 2009. Convenção de Viena sobre Direito dos Tratados, de 23 de maio de 1969. . 
[...] o contexto ao qual o Painel pode recorrer para fins de interpretação de determinados dispositivos do TRIPS [...] não está restrito ao texto, Preâmbulo e Anexos ao TRIPS, mas também inclui tanto os dispositivos de outros instrumentos internacionais sobre propriedade intelectual incorporados ao TRIPS, quanto qualquer outro acordo celebrado entre as partes relativos aos citados instrumentos internacionais, à luz do Art. 31(2) da Convenção de Viena sobre Direito dos Tratados. (Tradução nossa) ${ }^{32}$.

O painel, portanto, não só reconheceu o preâmbulo e os anexos ao TRIPS como componentes do contexto interpretativo, como acrescentou que disposições contidas em outros instrumentos internacionais sobre propriedade intelectual também podem contribuir para o esclarecimento do conteúdo normativo do tratado em questão, ampliando as possibilidades de instrumentos aos quais se poderia recorrer para elucidar o sentido de uma norma.

Uma conclusão fundamental derivada do Artigo 31 da Convenção de Viena é o princípio da efetividade. De fato, em United States - Standards for Reformulated and Conventional Gasoline, o Órgão de Apelação estabeleceu que:

[...] um dos corolários da regra geral de interpretação da Convenção de Viena é que a interpretação deve dar sentido e eficácia a todos os termos do tratado. O intérprete não é livre para adotar uma leitura que resultaria em reduzir cláusulas ou parágrafos inteiros de um tratado à redundância ou à inutilidade. (Tradução nossa) $)^{33}$.

$32[\ldots]$ the context to which the Panel may have recourse for purposes of interpretation of specific TRIPS provisions, $[\ldots]$ is not restricted to the text, Preamble and Annexes of the TRIPS Agreement itself, but also includes the provisions of the international instruments on intellectual property incorporated into the TRIPS Agreement, as well as any agreement between the parties relating to these agreements within the meaning of Article 31(2) of the Vienna Convention on the Law of Treaties. WORLD TRADE ORGANIZATION. Canada: term of patent protection AB-20007: report of the appellate body. WT/DS170/AB/R 18 September 2000. Conforme adotado em 18 de setembro de 2000. Para. 7.26.

33 One of the corollaries of the "general rule of interpretation" in the Vienna Convention is that interpretation must give meaning and effect to all the terms of a treaty. An interpreter is not free to adopt a reading that would result in reducing whole clauses or paragraphs of a treaty to redundancy or inutility. WORLD TRADE
A análise da Carta da OMC, a qual estabelece os objetivos e propósitos da Organização, bem como do preâmbulo de alguns de seus acordos constitutivos, são essenciais para a compreensão das normas contidas nos acordos da OMC. Com razão, qualquer sistema jurídico deve ser compreendido como um todo, sendo impossível se conhecer o real sentido de uma norma isoladamente ao ordenamento no qual se encontra inserida.

O preâmbulo do Acordo Geral Sobre Tarifas Aduaneiras e Comércio (GATT/1947), como o dos demais acordos que compõem o arcabouço normativo da OMC, apresenta os objetivos dos Estados contratantes quando da adoção do tratado. É possível se inferir do texto as distintas posições trazidas à negociação pelas partes, com clara sobreposição dos interesses dos países desenvolvidos em face dos em desenvolvimento e de menor desenvolvimento relativo.

\section{ACORDO GERAL SOBRE TARIFAS ADUANEIRAS E COMÉRCIO}

[...] Reconhecendo que suas relações no domínio comercial e econômico devem ser orientadas no sentido de elevar os padrões de vida, de assegurar o emprego pleno e um alto e sempre crescente nível de rendimento real e de produção efetiva, para a mais ampla exploração dos recursos mundiais e a expansão da produção e das trocas de mercadorias;

Almejando contribuir para a consecução desses objetivos, mediante a conclusão de acordos recíprocos e mutuamente vantajosos, visando à redução substancial das tarifas aduaneiras e de outras barreiras às permutas comerciais e à eliminação do tratamento discriminatório, em matéria de comércio internacional;

Por intermédio de seus representantes, convieram no seguinte ${ }^{34}$

É razoável se afirmar que os propósitos mais relevantes do GATT/47 à época de sua redação eram o

ORGANIZATION. United States: standards for reformulated and conventional gasoline. WT/DS2/9 20 may 1996. Conforme adotado em 20 de maio de 1996. p. 23.

34 Acordo Geral sobre Tarifas Aduaneiras e Comércio (GATT/1947). BRASIL. Decreto 313, de 30 de julho de 1948, 1948. 
de garantir a paz mundial, fomentar o desenvolvimento e o bem-estar econômico de todas as nações ${ }^{35}$.

O GATT/47 foi concebido tendo como fim o estabelecimento de mudanças nas legislações internas das partes contratantes para que fossem progressivamente reduzidas as barreiras ao comércio existentes. A interferência se dava, portanto, no âmbito de discricionariedade dos Estados e não na relação entre eles.

No texto do Acordo, é concedido enfoque particular à progressiva liberalização do comércio, conforme defendem os países desenvolvidos. Não obstante, o preâmbulo também apresenta como uns dos principais objetivos do GATT/47, a melhoria dos padrões de vida e a garantia do pleno emprego, o que retrata uma preocupação dos países em desenvolvimento com relação às implicações econômicas que poderiam advir da liberalização do comércio e que corresponde aos objetivos gerais da OMC.

Com efeito, o preâmbulo do Acordo Constitutivo da OMC inclui a maioria dos objetivos do GATT/47, ampliando-os:

As Partes do presente Acordo,

Reconbecendo que as suas relações na esfera da atividade comercial e econômica devem objetivar a elevação dos níveis de vida, o pleno emprego e um volume considerável e em constante elevação de receitas reais e demanda efetiva, o aumento da produção e do comércio de bens e de serviços, permitindo ao mesmo tempo a utilização ótima dos recursos mundiais em conformidade com o objetivo de um desenvolvimento sustentável e buscando proteger e preservar o meio ambiente e incrementar os meios para fazê-lo, de maneira compatível com suas respectivas necessidades e interesses segundo os diferentes níveis de desenvolvimento econômico,

Reconhecendo ademais que é necessário realizar esforços positivos para que os países em desenvolvimento, especialmente os de menor desenvolvimento relativo, obtenham uma parte do incremento do comércio

35 JACKSON, John Howard. Sovereignty, the WTO and changing fundamentals of international law. Cambridge: Cambridge University Press, 2006. p. 85-86. internacional que corresponda às necessidades de seu desenvolvimento econômico,

Desejosas de contribuir para a consecução desses objetivos mediante a celebração de acordos destinados a obter, na base da reciprocidade e de vantagens mútuas, a redução substancial das tarifas aduaneiras e dos demais obstáculos ao comércio, assim como a eliminação do tratamento discriminatório das relações internacionais,

Resolvidas, por conseguinte, a desenvolver um sistema multilateral de comércio integrado, mais viável e duradouro, que compreenda o Acordo Geral sobre Tarifas Aduaneiras e Comércio, os resultados de esforços anteriores de liberalização do comércio e os resultados integrais das Negociações Comerciais Multilaterais da Rodada Uruguai,

Decididas a preservar os princípios fundamentais e a favorecer a consecução dos objetivos que informam este sistema multilateral de comércio,

Acordam o seguinte: [...] (Grifo nosso) ${ }^{36}$

Ressalte-se que o preâmbulo de um tratado constitui importante ferramenta para sua interpretação, elucidando seu contexto, mas não impõe, por si, obrigações aos Estados-parte, como demonstrado pela própria conotação recomendatória dos verbos empregados. O dever de os tratados serem interpretados à luz de seus objetivos e propósitos é norma costumeira de Direito Internacional, conforme visto na seção 2.1.

A preocupação dos países em desenvolvimento e de menor desenvolvimento relativo no que tange às implicações econômicas decorrentes da liberalização do comércio encontra reflexo na afirmação de que todos os Membros devem cooperar para que aqueles obtenham uma parte dos ganhos do comércio internacional que corresponda às necessidades de seu próprio desenvolvimento econômico.

Nesse sentido, Amartya Sen, em sua obra Desenvolvimento como Liberdade ${ }^{37}$, propõe um conceito de desenvolvimento que se contrapõe à mera análise de fatores como o produto interno bruto, renda per capta,

36 Acordo Constitutivo da Organização Mundial Do Comércio. BRASIL. Decreto n. 1.355, de 30 de dezembro de 1994.

37 SEN, Amartya. Desenvolvimento como liberdade. Tradução: Laura Teixeira Motta. São Paulo: Companhia das Letras, 2010. p. 55. 
nível de industrialização e grau de desenvolvimento tecnológico de uma nação. Muito embora todos os fatores mencionados anteriormente contribuam para a expansão da capacidade de os indivíduos exercerem e usufruírem das suas liberdades, entende-se que o crescimento econômico, que é possibilitado pelo aumento dos fluxos comerciais internacionais, não pode ser considerado um fim em si mesmo, ele deve necessariamente estar associado com a melhoria dos padrões de vida de todos e, especialmente com a expansão das liberdades individuais.

A ideia de desenvolvimento como liberdade é oposta ao modelo clássico de desenvolvimento como aumento de renda real. A expansão das liberdades substantivas, como o aumento do acesso à educação, saúde e alimentação, é tida como resultado direto do processo de desenvolvimento econômico e está alinhada ao posicionamento adotado pelos países em desenvolvimento e de menor desenvolvimento relativo no seio da OMC.

O arcabouço normativo da OMC, especialmente quando se considera o preâmbulo dos seus acordos constitutivos, e os princípios e objetivos que regem a Organização, reflete valores que são partilhados por seus Membros: a busca do crescimento econômico não como um fim em si mesmo, mas como mecanismo que possibilite a expansão e o exercício pleno das liberdades individuais. Governança global se traduz, em última análise, em ações pautadas por valores compartilhados entre os vários atores, que podem ou não derivar de obrigações legalmente prescritas ${ }^{38}$. A Organização, portanto, exerce governança global, na medida em que funciona como um meio para que seus Membros busquem a realização de objetivos comuns.

\subsection{A boa governança na OMC}

Como anteriormente mencionado, a prática de boa governança dentro de uma Organização Internacional implica a observância de determinados princípios. $\mathrm{Na} \mathrm{OMC}$, tais princípios se correlacionam e podem ser encontrados em diversos acordos e aspectos institucionais da Organização. Há, contudo, melhorias que poderiam ser feitas de modo a reforçar o comprometimento da OMC com esses elementos basilares, o que promoveria o fortalecimento

38 ROSENAU; James N., CZEMPIEL, Ernst-Otto. Governance without government: order and change in world politics. Cambridge: Cambridge University Press, 2000. p. 4. da Organização e a satisfação do mandato de desenvolvimento assumido na Rodada Doha.

O primeiro desses princípios, o da legitimidade, será tratado com mais detalhes posteriormente, na análise da necessidade de reforma do sistema de tomada de decisão da OMC. A legitimidade pressupõe

$$
\begin{aligned}
& \text { especialidade e promessa de ganhos de bem-estar } \\
& \text { social; ordem e estabilidade; freios e contrapesos; } \\
& \text { diálogo político e um devido processo de } \\
& \text { formulação de decisão. (Tradução nossa) }{ }^{39} \text {. }
\end{aligned}
$$

Nesse sentido, esse conceito está intimamente relacionado às negociações e decisões delas decorrentes. Na OMC, a necessidade do consenso e da participação de todos os 160 membros nos fóruns de discussão evidencia a preocupação com a legitimidade do processo, de forma a garantir a estabilidade da Instituição, a persecução de seus objetivos e a excelência de suas atividades.

A direção, por sua vez, refere-se à consideração das diferentes perspectivas e fatores que influenciam as negociações sobre o comércio internacional. Nesse contexto, a noção de representatividade torna-se central. As iniciativas da OMC, como a realização de fóruns públicos, que aproximam a Organização da sociedade civil demonstram os esforços da OMC em identificar os interesses de uma esfera pública mais ampla. As redes verticais, ao desempenharem um papel de ponte, coordenando as negociações da OMC aos interesses e necessidades das unidades de governo dos membros e das sociedades civis internas de cada um deles, também se destacam como instrumentos essenciais para assegurar que um vasto leque de possibilidades e pontos de vistas sejam apreciados nas negociações.

A performance, por sua vez, abarca os conceitos de eficiência e eficácia. A eficiência relaciona-se com o tempo, recursos e custos envolvidos nas negociações e tomada de decisão. Já a eficácia envolve a observância dos acordos e das decisões da OMC por seus membros e a adequação desses instrumentos aos propósitos da Organização. A Rodada Doha apresenta-se como um desafio para esses dois aspectos. A dificuldade em se alcançar um consenso nos temas mais importantes da

39 expertise and the promise of social welfare gains; order and stability; checks and balances; political dialogue and a 'right process' for decision-making. ESTY, Daniel C. Good Governance at the World Trade Organization: building a foundation of administrative law. Journal of International Economic Law, v.10, n. 3, p. 509-527, 2007. p. 511. 
agenda, em uma negociação que se estende por treze anos, revela os problemas da OMC no que concerne a sua eficiência. Quanto à eficácia, o sistema de solução de controvérsias da Organização é um importante elemento para garantir que os seus membros cumpram as normas multilateralmente acordadas. Os obstáculos nesse ponto estão em assegurar a completa realização dos objetivos assumidos em seu acordo constitutivo, os quais, como anteriormente mencionado, envolvem o desenvolvimento e o bem-estar de todos os membros. O avanço desse princípio, assim como o da legitimidade, depende da reforma do processo da tomada de decisão da OMC, de modo a tornar o sistema realmente democrático e ativo no sistema multilateral do comércio.

No tocante à responsabilidade, as redes verticais na OMC também trariam benefícios para a solidificação desse princípio, pois facilitariam a responsabilização dos oficiais na Organização, de modo a garantir que eles atuem em consonância com as necessidades e interesses da sociedade internacional. A ligação, por meio de canais de comunicação e trabalho conjunto, entre os representantes eleitos internamente e os oficiais da OMC, permitiria a aproximação destes das realidades dos membros. As posturas assumidas nas negociações multilaterais seriam assim mais representativas e vinculadas aos padrões ali observados. A fiscalização, possibilitada pelo princípio da transparência, resultaria em um sistema de tomada de decisão mais congruente, com a necessidade de justificação das ações adotadas e das políticas aprovadas pela OMC.

Por fim, a justiça é um princípio que possui um elemento procedimental, relacionado ao devido processo e a oportunidade de ser ouvido, o que o aproxima muito do conceito de legitimidade, e um elemento substantivo, que pondera se os benefícios e encargos são equitativamente distribuídos ${ }^{40}$. $\mathrm{Na} \mathrm{OMC}$, o aspecto procedimental ainda necessita de maior atenção e a possibilidade de implementação de uma democracia deliberativa, como proposta no presente trabalho, apresenta-se como imprescindível para a sua completa realização. O caráter material de tal princípio é ressaltado nos diversos dispositivos estudados a seguir, que concedem tratamento especial e diferencial para os membros em desenvolvimento e de menor desenvolvimento relativo, de forma que estes não

40 ESTY, Daniel C. Good Governance at the World Trade Organization: building a foundation of administrative law. Journal of International Economic Law, v.10, n. 3, p. 509-527, 2007. p. 523. precisem arcar com um fardo maior na liberalização comercial.

\section{Países em desenvolvimento e a OMC}

Como abordado na seção anterior, são objetivos da OMC a melhoria dos padrões de vida, o pleno emprego, a promoção do desenvolvimento sustentável e ações afirmativas com o intuito de assegurar que os países em desenvolvimento e, especialmente, os de menor desenvolvimento relativo possam ter uma participação no crescimento do comércio mundial proporcional às suas necessidades de desenvolvimento econômico.

Acesso a mercados e crescimento de fluxos comerciais não necessariamente se convertem em desenvolvimento econômico efetivo, como se infere da lição de Amartya Sen:

É importante notar que opulência econômica e liberdade, ainda que não sejam dissociadas, podem frequentemente divergir. (Tradução nossa) ${ }^{41}$

A política comercial e, especialmente, a liberalização do comércio inevitavelmente provocam mudanças nas economias internas dos países afetados por tais políticas. Um comércio mais livre incentiva a expansão da atividade econômica, o que pode se traduzir em industrialização e aumento do consumo de recursos naturais, alterando o modelo de desenvolvimento até então adotado internamente. Este processo só estaria incluído no escopo da OMC, se fossem levados em conta o contexto interpretativo e os objetivos de seus acordos, na medida em que resultem na elevação dos padrões de vida, em formas de se assegurar o pleno emprego e em um alto e sempre crescente nível de rendimento real e de produção efetiva. Com razão,

[o] resultado básico sobre a eficiência do mercado pode, nesse sentido, ser estendido à perspectiva das liberdades substantivas. Mas esses resultados de eficiência nada dizem sobre a equidade das situações decorrentes, ou sobre a equidade na distribuição das liberdades ${ }^{42}$.

41 It is important to note that economic opulence and substantive freedom, while not unconnected, can frequently diverge. SEN, Amartya. The idea of justice. Cambridge: The Belknap Press of Harvard University Press, 2009. p. 226.

42 SEN, Amartya. Desenvolvimento como liberdade. Tradução: Laura Teixeira Motta. São Paulo: Companhia das Letras, 2010. p. 159-160. 
A rápida industrialização chinesa após a sua entrada na OMC exemplifica esta tendência. A transferência do excedente de mão de obra do setor agrícola, de baixa produtividade, para os setores secundários e terciários da economia, de alta produtividade, criou as bases para o rápido crescimento econômico do país, verificado na primeira década dos anos $2000^{43}$. Esse fenômeno resultou no aumento da população urbana, de 37.7\% em 2001, para $52 \%$ em $2013^{44}$. A opulência econômica, no entanto, não se converteu automaticamente em desenvolvimento humano.

A esse respeito, as considerações do Relatório do Desenvolvimento Humano de 2013:

\begin{abstract}
A ascensão do Sul abarca experiências de países muito distintos, mostrando que existem múltiplas formas de alcançar e manter o desenvolvimento humano. Os países foram pragmáticos na adoção de políticas adequadas às suas circunstâncias específicas: por exemplo, entre 1979 e 1989, nada mais nada menos que $40 \%$ da regulamentação nacional chinesa foi considerada de caráter experimental. Foram também amplamente partilhadas abordagens comuns. Verificou-se, na maioria dos países em rápido desenvolvimento do Sul, uma abertura ao exterior no domínio do comércio, investimento e tecnologia. Contudo, essa abertura não garantiu, por si só, o êxito. [...].

Uma liderança ativa por parte dos governos foi fundamental para acelerar o pregresso econômico e minimizar os conflitos sociais. [...] A China pôs igualmente em evidência a importância desta abordagem na sua procura estratégica de uma 'sociedade harmoniosa's .
\end{abstract}

O imperativo de se incorporarem as necessidades dos países em desenvolvimento e de menor desenvolvimento relativo ao sistema multilateral de

43 CHEN, Chunlai. China's integration with the global Economy: WTO accession, foreign direct investment and international trade. Cheltenham: Edward Elgar, 2009. p. 2.

44 DADOS do Banco Mundial. Disponível em: < http://data. worldbank.org/indicator/SP.URB.TOTL.IN.ZS>. Acesso em: 12 maio 2014

45 PROGRAMA DAS NAÇÕES UNIDAS PARA O DESENVOLVIMENTO - PNUD. Relatório do desenvolvimento humano 2013: a ascensão do sul: progresso humano num mundo diversificado. Disponível em: <http://www.un.cv/files/ HDR2013\%20Report\%20Portuguese.pdf> . Acesso em: 14 maio 2014. p. 18. comércio foi bem explicitado pelo relatório do Painel no caso EC - Tariff Preferences:

Durante a segunda sessão da UNCTAD, em 26 de março de 1968, uma Resolução sobre a "Expansão e Diversificação de Exportações e Manufaturas e SemiManufaturas em Países em Desenvolvimento" foi adotada (Resolução 21 (II)). Nesta resolução, a UNCTAD concordou com a "rápida criação de um sistema mutuamente aceitável de preferências generalizadas, não recíprocas e não discriminatórias, que seriam benéficas para os países em desenvolvimento" e estabeleceu uma Comissão Especial de Preferências como um órgão subsidiário do Conselho de Comércio e Desenvolvimento, com um mandato para decidir os detalhes de arranjos sobre Regime Generalizado de Preferências (RGP). Em 1970, a Comissão Especial de Preferências da UNCTAD aprovou as Conclusões Acordadas estabelecendo os detalhes acordados do regime SPG. O Conselho de Comércio e Desenvolvimento anotou estas Conclusões Acordadas em 13 de janeiro de 1970. De acordo com as Conclusões Acordadas, certos Membros desenvolvidos do GATT requereram a isenção do RGP perante o Conselho do GATT. O GATT concedeu uma isenção de 10 anos em 25 de junho de 1971. Antes de terminar o período de isenção, as Partes adotaram uma decisão em "Tratamento Diferencial e mais Favorável, Reciprocidade e Participação de Países em Desenvolvimento" (a "Cláusula de Habilitação”), em 28 de novembro de 1979. (Tradução nossa) ${ }^{46}$.

46 During the Second Session of UNCTAD, on 26 March 1968, a Resolution was adopted on "Expansion and diversification of Exports and Manufactures and Semi-manufactures of Developing Countries" (Resolution 21 (II)). In this Resolution, UNCTAD agreed to the "early establishment of a mutually acceptable system of generalized, non-reciprocal and non-discriminatory preferences which would be beneficial to the developing countries" and established a Special Committee on Preferences as a subsidiary organ of the Trade and Development Board, with a mandate to settle the details of the GSP arrangements. In 1970, UNCTAD's Special Committee on Preferences adopted Agreed Conclusions which set up the agreed details of the GSP arrangement.

UNCTAD's Trade and Development Board took note of these Agreed Conclusions on 13 January 1970. In accordance with the Agreed Conclusions, certain developed GATT contracting parties sought a waiver for the GSP from the GATT Council. The GATT granted a 10-year waiver on 25 June 1971. Before the expiry of this waiver, the CONTRACTING PARTIES adopted a decision on "Differential and More Favorable Treatment, Reciprocity and Fuller Participation of Developing Countries" (the "Enabling Clause") on 28 November 1979. EUROPEAN COMMUNITIES. Conditions 
A Cláusula de Habilitação, que permite que distorções geradas pela aplicação da Cláusula da Nação Mais Favorecida (MFN) sejam corrigidas com relação a países em desenvolvimento e de menor desenvolvimento relativo, é um dos instrumentos utilizados para se reduzirem as desigualdades verificadas entre os Membros. Ela se tornou um traço permanente tanto do GATT/47, quanto da OMC.

O tratamento preferencial, concedido sob a Cláusula de Habilitação, tem sido usado como forma de auxílio ao desenvolvimento, cujo objetivo final seria o de promover a expansão e a diversificação das exportações. A história, no entanto, sugere que o tratamento diferenciado, apesar de gerar incentivos à exportação, não é suficiente para superar os entraves internos à produção ${ }^{47}$.

Esse é um exemplo de como a consolidação de um regime comercial forte, fundamentado em regras jurídicas vinculantes, pode contribuir para a consolidação de um modelo abrangente de governança global no mercado mundial. $\mathrm{Na}$ ausência de hierarquia e de um poder central, são as normas que possibilitam a harmonia e a legitimação do sistema multilateral de comércio, por estimularem a inclusão de todos os atores em tal sistema. A Cláusula de Habilitação é um instrumento que oferece uma oportunidade para a correção dos desequilíbrios relacionados com a liberalização do comércio e o acesso a mercados.

Os acordos da OMC contêm aproximadamente cento e cinquenta e cinco dispositivos regulando o tratamento especial e diferenciado para países em desenvolvimento. Além da Cláusula de Habilitação, há exceções às regras gerais, metas reduzidas de diminuição de tarifas e de subsídios agrícolas, períodos mais extensos para a implementação interna das normas, regras procedimentais favoráveis e assistência técnica. Estes mecanismos são parte integrante dos acordos da OMC e são coerentes com os seus princípios e objetivos ${ }^{48}$. A correta aplicação destas regras contribui para a redução das assimetrias e fomento do desenvolvimento, sendo essenciais para o fortalecimento de uma verdadeira governança econômica global.

for the Granting of Tariff Preferences to Developing Countries (DS246), conforme adotado em 20 de abril de 2004.

47 HOEKMAN, Bernard M.; MAVROIDIS, Petros C. The World Trade Organization: law, economics and politics. Nova Iorque: Routledge, 2007. p. 95.

48 PANITCHPAKDI, Supachai. The WTO, global governance and development. In: SAMPSON, Gary P. (Ed.). The WTO and global governance: future directions. Tóquio: United Nations University Press, 2008. p. 188.
O reconhecimento de que o comércio pode servir como uma ferramenta de crescimento econômico, desenvolvimento e erradicação da pobreza também é encontrado na Declaração do Milênio das Nações Unidas:

\section{Declaração do Milênio das Nações Unidas}

[...] 12. Em consequência, decidimos criar condições propícias, a nível nacional e mundial, ao desenvolvimento e à eliminação da pobreza.

13. A realização destes objetivos depende, entre outras coisas, de uma boa governação em cada país. Depende também de uma boa governação no plano internacional e da transparência dos sistemas financeiros, monetários e comerciais. Propugnamos um sistema comercial e financeiro multilateral aberto, equitativo, baseado em normas, previsível e não discriminatório ${ }^{49}$.

Ao atrair investimentos domésticos e estrangeiros, incentivar o empreendedorismo e a produção, o aumento dos intercâmbios mercantis pode se converter, indubitavelmente, em desenvolvimento. Ao gerar renda, o comércio contribui para a criação de empregos, para o aumento da renda das populações, bem como para o aumento dos níveis de bem-estar de todos. No entanto, a realização destes objetivos não é automática. Depende da elaboração de políticas públicas que reconheçam a existência de assimetrias entre os atores e criem mecanismos para reduzi-las.

O fato de a Declaração do Milênio reconhecer que a boa governança em matéria comercial é essencial para a realização dos objetivos de promoção do desenvolvimento e de erradicação da pobreza é bastante significativo e demonstra que essa agenda não está circunscrita à OMC.

A chave para a realização das metas de desenvolvimento internacionalmente estabelecidas está na consolidação não apenas de um modelo de governança global, mas também de práticas de boa governança econômica global. A liberalização do comércio e aumento de acesso a mercados, por si só, não são suficientes para que haja efetiva melhoria no bem-estar de todos.

49 Declaração do Milénio das Nações Unidas é um documento histórico para o novo século. Aprovada na Cimeira do Milénio realizada de 6 a 8 de Setembro de 2000, em Nova Iorque. Disponível em: <https://www.unric.org/html/portuguese/uninfo/DecdoMil. pdf $>$. Acesso em: 14 maio 2014. 
6 A rodada Doha e a necessidade de reforma da OMC

As transformações observadas na sociedade internacional nas últimas décadas demonstram que não é mais possível ignorar a presença e o peso dos países em desenvolvimento na economia e políticas mundiais. A OMC tem tentado adaptar-se a esse contexto, de modo a abarcar os interesses e as necessidades deste grupo de Estados em suas atividades.

A Rodada Doha ${ }^{50}$ é a primeira rodada de negociações desde a instituição da OMC. Ela possui um propósito ambicioso, qual seja, o de revisar as normas já existentes e de ampliar o escopo regulatório da Organização, com a celebração de novos acordos. O tópico desenvolvimento tornou-se central nas discussões e passou a ser o fundamento para todas as negociações realizadas no âmbito da Rodada. Busca-se com isso amenizar os desequilíbrios decorrentes da Rodada do Urugua $^{51}$, pois, em razão da desproporcionalidade da capacidade negocial entre os países desenvolvidos e aqueles em desenvolvimento, os acordos resultantes desta Rodada acabaram por favorecer a prevalência dos interesses dos Estados economicamente mais fortes.

A conscientização dos Membros em desenvolvimento e de menor desenvolvimento relativo sobre o seu papel no sistema multilateral de comércio resultou na mudança da postura negocial desses países e, consequentemente, na evolução da dinâmica das negociações no interior da OMC. Observa-se uma posição mais incisiva e ativa desse grupo de Estados, que quer introduzir seus interesses e suas necessidades nas pautas de discussão.

Alguns dos Membros em desenvolvimento e de menor desenvolvimento relativo, temendo o desvio no propósito dos debates da Rodada Doha, decidiram se articular em uma coalizão, criando, em 2003, o G-20 comercial $^{52}$. O G-20 confere a esses países

50 Também conhecida como Rodada do Milênio, teve seu início em 2001, com um mandato voltado para o desenvolvimento.

51 Última Rodada de Negociações do GATT/47 que se estendeu de 1986 a 1994 e resultou na criação da OMC.

52 Grupo de países em desenvolvimento criado em 20 de agosto de 2003, na fase final da preparação para a V Conferência Ministerial da OMC, realizada em Cancun, entre 10 e 14 de setembro de 2003. O Grupo tem uma vasta e equilibrada representação geográfica, sendo atualmente integrado por 23 Membros: 5 da África (África do Sul, Egito, Nigéria, Tanzânia e Zimbábue), 6 da Ásia (China, Filipinas, Índia, Indonésia, Paquistão e Tailândia) e 12 da América Latina (Argentina, Bolívia, Brasil, Chile, Cuba, Equador, Guatemala, México, Paraguai, Peru, Uruguai e Venezuela), e concentra sua atuação em agricultura, o tema central da Agenda de Desenvolvimento de Doha. um maior poder de manobra e de persuasão, com o objetivo principal de proteger os compromissos sobre desenvolvimento assumidos na Agenda da Rodada Doha.

Desse modo, os Membros em desenvolvimento e de menor desenvolvimento relativo buscam alternativas para participar do sistema multilateral de comércio e para ter voz nas discussões e negociações, de forma a serem integrantes, de facto, da estrutura de cooperação fomentada pela governança global.

\subsection{Reforma do processo de tomada de decisão}

A OMC, a fim de solidificar, tanto em sua estrutura quanto em suas atividades, os princípios da boa governança mencionados nas seções anteriores, necessita rever o seu processo de tomada de decisões.

A regra que orienta esse processo é a do consenso. $\mathrm{O}$ grande problema no tocante a tal prática é que ela pode resultar em um impasse, o que, em algumas situações, leva à paralização nas negociações, como observado durante a Rodada Doha. As discussões sobre as formas de aprimorar esse método são muitas, mas nenhum resultado concreto foi alcançado. O consenso continua, assim, como a melhor alternativa para assegurar a legitimidade democrática das decisões, em especial quando comparado com o sistema de votos com pesos diferentes adotados, por exemplo, pelo Banco Mundial e pelo FMI. Depreende-se, pois, que deve necessariamente haver um acordo de vontades entre os Estados economicamente mais fortes e os Membros em desenvolvimento e de menor desenvolvimento relativo para que se alcance uma decisão na OMC..$^{53}$

A principal questão a ser analisada no tocante ao processo de tomada de decisão da OMC é como garantir aos Membros de menor poder político e econômico as oportunidades para manifestar seus interesses e necessidades. Torna-se necessário que esse grupo de países possa participar nas negociações de forma efetiva e seja capaz de influenciar as decisões que delas decorram.

A democratização do processo de tomada de decisão da OMC apresenta-se como um elemento necessário para a evolução da Organização e possui um contexto favorável para ser realizada, em razão

53 JACKSON, John H. Sovereignty, the WTO and changing fundamentals of international law. Cambridge: Cambridge University Press, 2006. p. 113-116. 
da ênfase concedida atualmente à governança global. A governança pressupõe a existência de negociações constantes, de modo a permitir a concordância sobre ações e regras comuns para responder a problemas também comuns ${ }^{54}$. A atuação conjunta, fundamental para a governança, apenas é possível quando todos os atores envolvidos no processo tenham as mesmas chances e os mesmos recursos para debater e para alcançar o resultado final, isto é, quando há a efetiva democratização do sistema.

A OMC é composta, atualmente, por cento e sessenta Membros, os quais, segundo as regras do consenso e do single undertaking, devem participar de todas as discussões e aceitar todas as regras multilateralmente acordadas. Percebe-se, assim, o desafio de assegurar a todos os países papel ativo nas negociações dentro da Organização.

Alguns autores sugerem como alternativa para superar esse problema a criação de grupos consultivos, de um comitê executivo, ou de um órgão consultivo ${ }^{55}$. Todas essas propostas possuem a mesma essência - a formação de um subgrupo, constituído por um número limitado de Membros, que atuaria como um órgão de apoio para as negociações, realizando estudos e análises técnicas sobre os temas debatidos no fórum multilateral. A despeito do temor de alguns Estados, tal subgrupo não seria um instrumento de exclusão, uma vez que emitiria pareceres recomendatórios e não decisões vinculatórias, suas atividades seriam imparciais e transparentes, e haveria uma rotação periódica dos participantes, o que garantiria a sua representatividade e diversidade. O propósito seria fornecer substrato material para as discussões, como forma de ajudar na construção de argumentos dos Membros.

54 LAMY, Pascal. The WTO's Contribution to Global Governance. In: SAMPSON, Gary P. (Ed.). The WTO and global governance: future directions. Tóquio: United Nations University Press, 2008. p. 41.

55 Nesse sentido, conferir: OSTRY, Sylvia. The WTO, global governance and policy options. In: SAMPSON, Gary P. (Ed.). The WTO and global governance: future directions. Tóquio: United Nations University Press, 2008; SUTHERLAND, Peter; SEWELL, John; WEINER David. Challenges Facing the WTO and Policies to Address Global Governance. In: SAMPSON, Gary P. (Ed.). The Role of the World Trade Organization in global governance. Tóquio: United Nations University Press, 2001; BLACKHURST, Richard; HARTRIDGE, David. Improving the Capacity of WTO Institutions to Fulfil Their Mandate. Journal of International Economic Law, v.7, n. 3, p. 705-716, 2004.
A teoria da democracia discursiva ${ }^{56}$ apresenta-se como a mais adequada para a governança global, em que há uma reafirmação dos países em desenvolvimento na sociedade internacional. A aplicação dessa teoria significaria oestabelecimento de mecanismosdefomento a uma atuação coordenada dos Membro na OMC, de modo a promover um consenso fundamentado ${ }^{57}$. O fato de haver reconhecimento, respeito e igualdade de todas as partes como integrantes da ação comunicativa não nega a assimetria de poder entre elas, mas salienta que os aspectos relacionados ao poder, coerção e força devem ser colocados em segundo plano, priorizando-se os argumentos e os melhores fundamentos ${ }^{58}$.

Dessa forma, é possível

[...] avaliar reflexivamente e coletivamente as reinvindicações válidas sobre normas e padrões de comportamento estabelecidos. Como resultado, argumentação e persuasão constituem ferramentas de "direção branda" que podem melhorar tanto os problemas de legitimidade da governança global, por prover oportunidades para os diversos interessados em expressar sua voz, quanto a capacidade de solução de problemas das instituições de governança por intermédio da deliberação (Tradução nossa) ${ }^{59}$.

O objetivo final da democratização do processo de tomada de decisões é conseguir um sistema legítimo,

56 A democracia discursiva, ou democracia deliberativa, é uma teoria desenvolvida a partir dos estudos de Habermas, que se baseia na argumentação e na ação comunicativa. Diferentemente da democracia representativa, na qual há o enfoque no voto por cabeça, a democracia discursiva enfatiza os discursos dos atores e a institucionalização de processos para garantir que esses discursos sejam externalizados e considerados na tomada de decisão. Uma decisão adequada, legítima e democrática será, segundo essa corrente, aquela que aprecia todas as perspectivas apresentadas pelos diferentes discursos e é justificada pelos melhores argumentos. Desse modo, a democracia discursiva ressalta a pluralidade das partes e favorece a integração de diferentes realidades.

57 HABERMAS, Jürgen. The theory of communicative action: Reason and the rationalization of society. Boston: Beacon Press, 1984. p. 285-286.

58 RISSE, Thomas. Global governance and communicative action. Government and Opposition, v. 39, n. 2, p. 288-313, 2004. p. 296.

$59[\ldots]$ can reflexively and collectively assess the validity claims of norms and standards of appropriate behavior. As a result, arguing and persuasion constitute tools of 'soft steering' that might improve both the legitimacy problems of global governance by providing voice opportunities to various stakeholders and the problem-solving capacity of governance institutions through deliberation. RISSE, Thomas. Global governance and communicative action. Government and Opposition, v. 39, n. 2, p. 288-313, 2004. p. 288-289. 
que produza decisões igualmente legítimas, mas que seja eficaz, capaz de superar os entraves das negociações.

Nesse mesmo contexto, é imprescindível aprimorar a transparência e a participação dos Membros nas atividades desenvolvidas no seio da Organização.

A transparência é um princípio que norteia a atuação da OMC e está presente em seus acordos, constituindo-se uma via de mão dupla: os Membros devem publicar suas políticas relacionadas ao comércio internacional e a Organização deve tornar públicas as suas decisões e todo trabalho relacionado às negociações. Assim, os documentos produzidos no interior da $\mathrm{OMC}$, tanto por seus funcionários quanto por representantes governamentais, devem ser públicos e práticas que tentem burlar esse princípio, como por exemplo, conceder caráter não oficial a documentos que são, de fato, oficiais, devem ser coibidas. Além disso, questiona-se o fato de o Sistema de Solução de Controvérsias não ser aberto aos outros Membros que não estejam envolvidos na disputa, e a dificuldade dos comitês e grupos de trabalho em tornarem suas reuniões mais transparentes ${ }^{60}$.

A participação, por sua vez, está atrelada ao princípio da transparência e implica mais que a mera presença de alguns representantes governamentais junto à sede da OMC em Genebra. Ela é condição essencial para a garantia de legitimidade da OMC, uma vez que uma decisão da Organização será legítima se produzida por um sistema inclusivo que permita aos Membros uma contribuição em igual medida e o acesso às informações necessárias para a construção de suas perspectivas. Um passo importante para assegurar a efetiva participação dos Membros é o fornecimento de expertise e condições materiais adequadas, com destaque para o princípio da cooperação, que permite a capacitação técnica dos países em desenvolvimento e de menor desenvolvimento relativo.

Dessa forma, investir em aspectos como transparência, participação e cooperação favorecem a imparcialidade, a representatividade e a legitimidade das decisões, na medida em que esses princípios são essenciais para assegurar o acesso às informações e ao conhecimento. Esses elementos são necessários para o equilíbrio de poder entre os Membros, bem como

60 JACKSON, John H. Sovereignty, the WTO and Changing fundamentals of international law. Cambridge: Cambridge University Press, 2006, p. 118-120. para o desenvolvimento de posições e a articulação de interesses no decorrer das negociações.

Os fóruns de discussão existentes na OMC são uma característica que singulariza esta Organização perante as demais, mas é mandatório que o formato deles seja repensado, com base em uma teoria democrática discursiva, de modo a apreciar todos os pontos de vista apresentados pelos países. Nesse mesmo processo, devem-se considerar os princípios de boa governança e realçar a noção de comunidade que sustenta a estrutura da OMC e que é o alicerce para o êxito da Organização. A exposição das diferentes posições permite a persuasão por meio dos melhores argumentos e assegura que a decisão adotada será aquela mais bem fundamentada e que ofereça maiores benefícios para o sistema multilateral de comércio, ao mesmo tempo em que promova o desenvolvimento.

\section{Conclusão}

Os temas de governança econômica global, relacionados com o desenvolvimento, devem considerar os problemas dos países emergentes e as suas implicações para o sistema multilateral de comércio. A credibilidade e a viabilidade de um sistema multilateral de comércio durável estão intrinsecamente relacionadas com a capacidade de as normas sobre comércio internacional e a própria OMC preencherem o seu potencial de atuarem como instrumentos de promoção do desenvolvimento.

Como visto, a melhoria pura e simples dos indicadores econômicos não é suficiente para a criação de um ambiente internacional capaz de fomentar o desenvolvimento e o crescimento econômico sustentável. Nesse cenário, o fortalecimento dos elementos fundamentais da governança global econômica pode desempenhar um papel central na criação das bases para esse desenvolvimento e crescimento econômico sustentável.

Por um lado, a instituição da OMC e de normas uniformes sobre comércio contribuíram para $O$ aumento dos intercâmbios mercantis, por meio da progressiva remoção das barreiras ao comércio, do aumento da transparência e da previsibilidade das normas comerciais.

Por outro lado, é imprescindível que os acordos da OMC sejam interpretados de forma a incentivar o desenvolvimento, colocando as necessidades e 
interesses dos países em desenvolvimento e de menor desenvolvimento relativo no centro das negociações.

É verdade que as negociações comerciais tendem a refletir as relações de poder existentes, favorecendo a conclusão de negociações referentes a temas afetos à agenda dos países desenvolvidos, como o estabelecimento de exceções à liberalização do comércio em áreas nas quais são pouco eficientes, como agricultura e têxteis.

Não obstante todos esses desafios, a recente Rodada de Negociação oferece a oportunidade para a correção dos desequilíbrios verificados ao longo dos vinte anos da celebração dos Acordos de Marraqueche. Os esforços no sentido de redução das assimetrias e fomento do desenvolvimento são essenciais para o fortalecimento de uma verdadeira governança econômica global.

O desafio que se apresenta para os formuladores de políticas públicas e legisladores é como incentivar o desenvolvimento inclusivo, que não apenas se manifeste na forma de ingresso de receitas, mas também de melhoria dos índices de desenvolvimento humano da população envolvida no processo; e, ao mesmo tempo, preservar as características principais do já estabelecido sistema multilateral de comércio, para que ele perdure para além dos ciclos de expansão e de recessão da economia.

A importância da OMC e do sistema que se constituiu sob os seus auspícios é inquestionável. Os acordos e regras em vigor, ao lado de um sistema efetivo e bem estabelecido de solução de controvérsias, asseguram a sua relevância para um mundo de economia globalizada. Seu caráter universal, confirmado pela acessão da China (2001) e, recentemente, da Rússia (2012), confere ainda maior legitimidade à Organização.

A responsabilidade pela construção de um sistema equilibrado e efetivamente integrado, dotado da flexibilidade necessária para que haja espaço na arena política para que os países em desenvolvimento e de menor desenvolvimento relativo possam sustentar o seu crescimento é de todos os seus Membros e, especialmente, das economias mais avançadas. Sempre que estas demonstram vontade política, a conclusão das negociações se dá de maneira mais fácil. 


\section{Referências}

BENTO, Leonardo Valles. Governança global: uma abordagem conceitual e normativa das relações internacionais em um cenário de interdependência e globalização. 2007. Tese (Doutorado)-Curso de PósGraduação em Direito, Universidade Federal de Santa Catarina, Florianópolis, 2007.

BLACKHURST, Richard; HARTRIDGE, David. Improving the Capacity of WTO Institutions to Fulfil Their Mandate. Journal of International Economic Law, v.7, n. 3, p. 705-716, 2004.

BRASIL. Decreto 313, de 30 de julho de 1948. Acordo geral sobre tarifas e comércio, de 15 de abril de 1994.

BRASIL. Decreto n. 1.355, de 30 de dezembro de 1994.

BRASIL. Decreto n. 21.177, de 27 de maio de 1946. Convênio constitutivo do Fundo Monetário Internacional - FMI, de 22 de julho de 1944. Disponível em: <http://data. worldbank.org/indicator/SP.URB.TOTL.IN.ZS>. Acesso em: 12 maio 2014.

BRASIL. Decreto n. 25.696, de 20 de Outubro de 1948. Constituição da Organização Internacional do Trabalho (OIT).

BRASIL. Decreto n. 7.030, de 14 de dezembro de 2009. Convenção de Viena sobre Direito dos Tratados, de 23 de maio de 1969.

BRASIL. Decreto no 1.355 , de 30 de dezembro de 1994. Entendimento da OMC sobre regras e procedimentos para a solução de controvérsias, de 15 de abril de 1994.

CHEN, Chunlai. China's integration with the global Economy: WTO accession, foreign direct investment and international trade. Cheltenham: Edward Elgar, 2009.

ESTY, Daniel C. Good Governance at the World Trade Organization: building a foundation of administrative law. Journal of International Economic Law, v.10, n. 3, p. 509-527, 2007.

ESTY, Daniel C. Governing at the trade-environment interface. In: SAMPSON, Gary P. (Ed.). The WTO and global governance: future directions. Tóquio: United Nations University Press, 2008.
FINKELSTEIN, Lawrence S. What is global governance? Global Governance, v. 1, n. 3, p. 367-373, sept./dec. 1995.

GRAHAM, John; AMOS, Bruce; PLUMPTRE, Tim. Principles for Good Governance in the 21st Century. August 2003. Ottaw: Institute of Governance, 2003. (Policy Brief, n. 15). Disponível em: <http://unpan1. un.org/intradoc/groups/public/documents/UNPAN/ UNPAN011842.pdf>. Acesso em: 12 out. 2014.

HABERMAS, Jürgen. The theory of communicative action: reason and the rationalization of society. Boston: Beacon Press, 1984.

HOBSBAWN, Eric. The age of extremes: the short twentieth century (1914-1991). Londres: Abacus, 1994.

HOEKMAN, Bernard M.; MAVROIDIS, Petros C. The World Trade Organization: law, economics and politics. Nova Iorque: Routledge, 2007.

INSTITUTO BRASILEIRO DE MINERAÇÃO - IBRAM. Informações e Análise da Economia Mineral Brasileira. 7. ed. Dez. de 2012. Disponível em: <http:// www.ibram.org.br/sites/1300/1382/00002806.pdf>. Acesso em: 14 maio 2014.

INSTITUTO BRASILEIRO DE MINERAÇÃO IBRAM. Relatório Anual IBR AM: julho 2012 - junho 2013. Disponível em: <http://www.ibram.org.br/ sites $/ 1400 / 1457 / 00000383$.pdf $>$. Acesso em: 14 maio 2014.

JACKSON, John Howard. Sovereignty, the WTO and changing fundamentals of international law. Cambridge: Cambridge University Press, 2006.

KEYNES, John Maynard. The Great Slump of 1930: part 1. Londres: The Nation \& Athenæum, 1930. Disponível em: <http://www.gutenberg.ca/ebooks/ keynes-slump/keynes-slump-00-h.html $>$. Acesso em: 29 out. 2014.

LAMY, Pascal. The WTO's Contribution to Global Governance. In: SAMPSON, Gary P. (Ed.). The WTO and global governance: future directions. Tóquio: United Nations University Press, 2008.

NAÇÕES UNIDAS. Declaração do Milénio. Aprovada na Cimeira do Milénio. Realizada de 6 a 8 de setembro de 
2000, em Nova Iorque. Disponível em: <https://www. unric.org/html/portuguese/uninfo/DecdoMil.pdf $>$. Acesso em: 14 maio 2014.

OSTRY, Sylvia. The WTO, Global Governance and Policy Options. In: SAMPSON, Gary P. (Ed.). The WTO and global governance: future directions. Tóquio: United Nations University Press, 2008.

PALMETER, David; MAVROIDS, Petros C. Dispute Settlement in the World Trade Organization: practice and procedure. 2. ed. Cambridge: Cambridge University Press, 2004.

PANITCHPAKDI, Supachai. The WTO, global governance and development. In: SAMPSON, Gary P. (Ed.). The WTO and global governance: future directions. Tóquio: United Nations University Press, 2008.

PROGRAMA DAS NAÇÕES UNIDAS PARA O DESENVOLVIMENTO - PNUD. Relatório do desenvolvimento bumano 2013: a ascensão do sul: progresso humano num mundo diversificado. Disponível em: <http://www.un.cv/files/HDR2013\%20Report $\% 20$ Portuguese.pdf $>$. Acesso em: 14 maio 2014.

RISSE, Thomas. Global governance and communicative action. Government and Opposition, v. 39, n. 2, p. 288-313, 2004.

ROSENAU; James N., CZEMPIEL, Ernst-Otto. Governance without government: order and change in world politics. Cambridge: Cambridge University Press, 2000.

SEN, Amartya. Desenvolvimento como liberdade. Tradução: Laura Teixeira Motta. São Paulo: Companhia das Letras, 2010.
SEN, Amartya. The idea of justice. Cambridge: The Belknap Press of Harvard University Press, 2009.

SLAUGHTER, Anne-Marie. A new world order. Princeton: Princeton University Press, 2004.

SOMAVIA, Juan. Promoting policy coherence in the global governance of trade and employment. In: SAMPSON, Gary P. (Ed.). The WTO and global governance: future directions. Tóquio: United Nations University Press, 2008.

SUTHERLAND, Peter; SEWELL, John; WEINER David. Challenges Facing the WTO and Policies to Address Global Governance. In: SAMPSON, Gary P. (Ed.). The Role of the World Trade Organization in global governance. Tóquio: United Nations University Press, 2001.

WORLD TRADE ORGANIZATION. Canada: term of patent protection $\mathrm{AB}-2000-7$ : report of the appellate body. WT/DS170/AB/R 18 September 2000. Conforme adotado em 18 de setembro de 2000.

WORLD TRADE ORGANIZATION. Japan: taxes on alcoholic beverages: report of the appellate body. (Japan - Alcoholic Beverages II), WT/DS8/AB/R; WT/DS10/AB/R; WT/DS11/AB/R. 4 October 1996. Como adotado em 1 de novembro de 1996.

WORLD TRADE ORGANIZATION. United States: standards for reformulated and conventional gasoline. WT/DS2/9 20 may 1996. Conforme adotado em 20 de maio de 1996. 
Para publicar na Revista de Direito Internacional, acesse o endereço eletrônico www.rdi.uniceub.br ou www.brazilianjournal.org.

Observe as normas de publicação, para facilitar e agilizar o trabalho de edição. 